\title{
LA EMERGENCIA DEL DISCURSO SOCIALISTA EN LA FEDERACIÓN OBRERA DE CHILE: LAS POLÉMICAS DE PRENSA ENTRE GENTOSO Y RECABARREN
}

\author{
Francisca Durán Mateluna ${ }^{1}$
}

\section{Resumen/Abstract}

El presente artículo aborda la emergencia e incorporación del discurso socialista en la Federación Obrera de Chile entre 1913 y 1915, mediante la disputa y enfrentamiento ideológico en la prensa obrera entre Eduardo Gentoso, militante demócrata, miembro de la Federación Obrera de Chile (FOCH) y columnista del periódico La Locomotora de Santiago y Luis Emilio Recabarren, fundador y miembro del Partido Obrero Socialista (POS) y columnista de El Despertar de los Trabajadores de Iquique. Esta controversia fue el punto de encuentro -o desencuentro y fricción- entre la FOCH y el socialismo. Este artículo, con objeto de ampliar la discusión en torno a la emergencia e instalación del socialismo en la FOCH, propone develar las distintas comprensiones, valoraciones y temporalidades en la instalación discursiva del socialismo, permitiendo entender el discurso no como una categoría fija y estática, sino que, como una práctica social y parte de un proceso histórico en el cual perviven elementos anteriores y emergen otros, arrojando así sentidos distintos de acuerdo a los contextos.

Palabras clave: Federación Obrera de Chile, socialismo, Luis Emilio Recabarren, Eduardo Gentoso, discurso emergente, prensa obrera

\section{THE EMERGENCY OF THE SOCIALIST SPEECH IN THE WORK FEDERATION OF CHILE: THE} PRESS CONTROVERSY BETWEEN GENTOSO AND RECABARREN

This article addresses the emergence and incorporation of socialist discourse in the Worker's Federation of Chile between 1913 and 1915, through the dispute and ideological confrontation in the workers' press between Eduardo Gentoso, Democratic militant, member of the Chilean Workers Federation (FOCH) and columnist of the newspaper La Locomotora de Santiago, and Luis Emilio Recabarren, founder and member of the Socialist Workers Party (POS) and columnist for El Despertar de los Trabajadores of Iquique. This controversy was the meeting point -or disagreement and friction-between FOCH and socialism. This article, in order to broaden the discussion about the emergence and installation of socialism in the FOCH, proposes to unveil the different understandings, valuations and temporalities in the discursive installation of socialism, allowing to understand the discourse not as a fixed and static category, but, as a social practice and part of a historical process in which previous elements survive and others emerge, thus throwing different senses according to the contexts

Keywords: Chilean Workers Federation, socialism, Luis Emilio Recabarren, Eduardo Gentoso, emerging discourse, workers press

\footnotetext{
${ }^{1}$ Universidad Católica de Chile. E-mail: franciscaduranm@gmail.com
} 


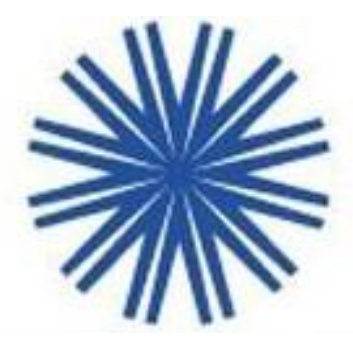

\section{Introducción}

El propósito de este artículo es analizar la emergencia e incorporación del discurso socialista en la Federación Obrera de Chile (en adelante FOCH) entre 1913 y 1915. Para abordar este problema nos centraremos en la disputa y enfrentamiento ideológico en la prensa obrera entre Eduardo Gentoso, militante demócrata, miembro de la FOCH y columnista del periódico La Locomotora de Santiago y Luis Emilio Recabarren, fundador y miembro del Partido Obrero Socialista (POS) y columnista de El Despertar de los Trabajadores de Iquique ${ }^{2}$.

La FOCH, en el momento de la institucionalización del socialismo obrero en el POS en 1912, bajo el liderazgo de Recabarren, no pertenecía propiamente al mundo socialista; sus formulaciones no tenían puntos de contacto con la declaración de principios ni con el programa político del naciente partido obrero ${ }^{3}$ (Pinto, 1999:318). De hecho, la FOCH no se identificaba con este ideario. Sin embargo, los entonces dirigentes de la FOCH no criticaban el pensamiento socialista, aunque sí la intransigencia que tuvo el POS, específicamente la postura de su principal líder hacia sus prácticas y discursos.

A partir de estas críticas comenzó en diciembre de 1913 una polémica entre Recabarren y Gentoso en torno a los significados del socialismo, sus métodos de lucha y el sentido de ser socialista ${ }^{4}$. Como veremos, esta controversia fue el punto de encuentro -o desencuentro y fricción- entre la FOCH y el socialismo.

Los trabajadores ferroviarios ligados a la FOCH, en el contexto en que irrumpieron los conceptos socialismo y socialista, mantenían su perfil mutualista abocados a reforzar los derechos y previsiones laborales y a incentivar la instrucción y el ingreso de los ferroviarios a la Federación. En esta lógica, la

\footnotetext{
${ }^{2}$ La controversia se inició en diciembre de 1913 cuando Eduardo Gentoso publicó en La Locomotora una serie de artículos titulados "Sectarismo Socialista", "Intolerancia y Socialismo" y "Recabarren y el Socialismo", "Recabarren y la Federación", entre otros, en respuesta a las impugnaciones de Luis Emilio Recabarren hechas en El Despertar de los trabajadores. El último artículo relacionado con la polémica titulado "La Democracia y el Socialismo. Gentoso versus Recabarren" fue publicado el 6 de junio de 1914.

${ }^{3}$ Cuya declaración de principios contemplaba: "la abolición de la propiedad privada, la asunción del poder político de la clase trabajadora, y la sustitución del régimen social existente por otro en que se desvaneciera el Estado y las diferencias de clases". ${ }^{4}$ La trayectoria del pensamiento socialista de Recabarren, se abordó en relación a sus influencias externas y representaciones del socialismo y, cómo estas influyeron en la producción del discurso y en las representaciones del socialismo de la FOCH a lo largo de este periodo. El libro de Jaime Massardo, La formación del imaginario político de Luis Emilio Recabarren. Contribución al estudio crítico de la cultura política de las clases subalternas de la sociedad chilena (2008), fue una puerta de entrada para analizar esta temática. En cuanto a Eduardo Gentoso, su imaginario político ha sido más difícil de reconstruir, puesto que las referencias históricas y bibliográficas son escasas. El registro más acabado de su trabajo político y periodístico se encuentra en López, Osvaldo, Diccionario biográfico obrero, (1912). No obstante, su biografía sólo aborda hasta 1914, luego su recorrido gremial y político se torna más difuso y fragmentado.
} 
FOCH desde 1911 promovió la política de abrir sus puertas a toda persona, cualquiera fuese su credo religioso o político, sin asignar otro límite que el impuesto por su estatuto. En términos de conducción, continuaban ligados a su presidente honorario, el conservador Paulo Marín Pinuer, aunque comenzaron a aparecer los primeros signos de distanciamiento entre él y la FOCH. No obstante, esta emergencia discursiva socialista, manifiesta en disputas y enfrentamientos ideológicos, apareció en un contexto de transición de la $\mathrm{FOCH}$, dado por su condición federativa, estable, reivindicativa y abierta a otros gremios, lo cual la proyectaba como una organización gremial que no se definía sólo por su discurso mutualista sino que como un sindicato de corte moderno ${ }^{5}$.

Este artículo, asimismo, con objeto de ampliar la discusión en torno a la emergencia e instalación del socialismo en la FOCH, y no remitir su significado sólo al arribo de Recabarren en la convención de Concepción de 1919, propone develar las distintas comprensiones, apropiaciones, valoraciones y temporalidades en la instalación discursiva del socialismo, permitiendo, de esta forma, entender el discurso no como una categoría fija y estática sino que como una práctica social, parte de un proceso histórico en el cual perviven elementos anteriores y emergen otros, arrojando así sentidos distintos de acuerdo a los contextos. De este modo, se puede relacionar dicho proceso discursivo de la FOCH con los cambios en sus prácticas y estrategias de movilización; es decir, con las lógicas relacionales de los federados con el Estado para solucionar sus conflictos laborales y los cambios de orientación política, como el giro que comenzó a dar hacia la izquierda, dejando atrás su impronta mutualista ${ }^{6}$.

El análisis de la incorporación del discurso socialista en la FOCH, se plantea a partir del juego de lo hegemónico o dominante, residual y emergente ${ }^{7}$, anudando así un proceso heterogéneo que posee ritmos

\footnotetext{
${ }^{5}$ Nos referimos a un tipo de sindicato con demandas específicas, liderazgos reconocibles y la utilización de la huelga como principal medio de presión sobre los capitalistas. Fue crucial en esto, la mayor importancia que fueron tomando las doctrinas de redención social como el anarquismo y el socialismo (Grez 2000).

${ }^{6}$ La transformación de la FOCH entre 1913 y 1919 supuso la incipiente instalación del socialismo en términos discursivos visible en los textos y polémicas de prensa y en la presencia de trabajadores que se identificaban con este ideario-, lo cual habilitó el camino para implementar los cambios requeridos tras la Convención de 1919, la que expresó a través de una nueva declaración de principios y nuevo estatuto, su orientación clasista y revolucionaria y la conducción bajo la égida del socialismo de Recabarren, constituyéndose en el discurso dominante. Esta es la principal hipótesis de la tesis para optar al grado de Magíster, "El discurso socialista en la Federación Obrera de Chile: lucha discursiva y juego de lo hegemónico, residual y emergente en la prensa obrera, 1913-1919", de Francisca Durán Mateluna.

${ }^{7}$ Esta perspectiva cultural de lo ideológico permite identificar el desplazamiento de los discursos desde uno hegemónico a la instauración de otro y cómo se fue incorporando y desplegando el socialismo en el escenario de la FOCH, primero en el ámbito de lo emergente y luego transformándose en el discurso hegemónico, quedando el discurso hegemónico inicial en el ámbito de lo residual. En otras palabras, esta perspectiva considera el tránsito desde la retórica conservadora a la demócrata y desde la emergente retórica socialista al socialismo recabarrenista.
} 
diferentes y que no es lineal, en el cual resaltan las dimensiones del "conflicto" entre sujetos concretos y la ambivalencia conceptual y práctica en torno a los idearios políticos y militancias del mundo obrero de la época. Estas nociones están integradas a un marco temporal acotado de la historia de la FOCH, pero suficiente para identificar en su seno la emergencia del discurso socialista. Entenderemos por discursos emergentes a aquellos "que elaboran nuevos significados y valores, nuevas prácticas y nuevos tipos de relaciones que se crean continuamente. Estos discursos provocan una ruptura respecto de lo dominante, pero a su vez sólo pueden producirse en relación con un sentido cabal de lo dominante" (Williams, 1980: 145-146).

\section{Matrices socialistas de principios del siglo $X X$}

El análisis de la incorporación del discurso socialista en la FOCH supone precisar ciertas nociones en torno al socialismo y sus representaciones no sólo en el momento de la formación del POS (1912) y de las polémicas que se suscitaron en la FOCH (1913) producto de la emergencia e instalación de los conceptos "socialismo" y "socialista" en sus discursos. No obstante, se debe tener en cuenta que el socialismo en América Latina como pensamiento y acción, y con él la difusión de concepciones de matriz marxista, sólo comenzó a evidenciarse hacia fines del siglo XIX, por tanto, corresponde situar al socialismo local en una perspectiva más amplia que considere su carácter novedoso y foráneo y, a su vez, las vicisitudes de su aplicación en el contexto latinoamericano y nacional.

Si bien este artículo no aborda los obstáculos que tuvo la difusión del marxismo en un contexto histórico diferente de aquel en que se constituyó como doctrina -debido a los efectos de la introducción y el desarrollo del capitalismo en América Latina como explica José Aricó-, su anuncio permite distinguir dos aspectos a priori sobre el socialismo latinoamericano y que son analizados profusamente por este autor. El primero, se refiere a que no es posible homologar socialismo y movimiento obrero, como sí ocurrió en Europa, puesto que en América Latina constituyeron dos historias paralelas que en contadas ocasiones se identificaron y que en la mayoría de los casos se mantuvieron ajenas y hasta opuestas entre sí. Y el segundo, se refiere a la morfología concreta y diferenciada que tuvo en nuestra región el proceso de constitución de un proletariado "moderno", aspecto que fija las condiciones y modalidades de los niveles globales de la lucha de clases y por tanto la forma de la teoría (Arico, 1999:23). 
En vista de estos dos aspectos, se comprende, entonces, que la forma de la teoría en el escenario continental estuvo sujeta a las características "cosmopolitas" de toda clase obrera naciente más que a la elaboración de nociones teóricas propias e inéditas. En este sentido, los principios teóricos que rodearon al socialismo en estas primeras décadas del siglo XX provinieron de la experiencia de la organización de partidos socialistas europeos, conocida como Segunda Internacional o también llamada Internacional Socialista (1889-1914), instalada sobre la creencia, al igual que el espíritu que impregnó a la Primera Internacional (1864-1876), que para combatir el sistema capitalista era necesario la unión de los trabajadores más allá de las fronteras nacionales. Sin embargo, esto no implicó un conocimiento profundo del marxismo, es más, como precisó Aricó (1999) a propósito de la recepción en el pensamiento social latinoamericano, "Marx era uno más de una vasta pléyade de reformadores sociales que las deficientes ediciones españolas traducían mal del francés" (40). En tanto término, "marxismo" se incorporó al vocabulario político después de la Revolución rusa de 1917, adquiriendo un carácter más definido cuando en los años veinte lo asumieron los partidos comunistas latinoamericanos recientemente formados (40). Pese al desconocimiento de la obra de Marx, sí circularon algunas publicaciones de destacados socialistas adscritos a la Internacional, divulgándose así, en parte, las ideas socialistas. Entre estas destacó la revista Die Neue Zeit, órgano de la socialdemocracia alemana dirigido por Karl Kautsky, leída principalmente en Argentina (Aricó 1999, Massardo 2008).

La socialdemocracia alemana (SDP), por su parte, desde su victoria electoral en febrero de 1890 y la derogación de las leyes "antisocialistas" en agosto de 1891, se expresó como una gran fuerza política iniciadora de una nueva época en la historia del movimiento obrero, siendo junto a los socialistas franceses el sector más influyente y predominante en la Internacional Socialista hasta 1914 (momento en que la organización firmó su sentencia de muerte frente al destino inexorable de la primera guerra mundial). De este modo, la socialdemocracia alemana se convirtió en el partido dirigente de la Internacional y en el modelo mundial de partido socialista debido a su fuerza organizativa y parlamentaria en ascenso. Aricó expresa que esa referencia se trasvasó a América Latina en "su visión del marxismo como ideología del desarrollo y la modernización en el interior de una insuprimible lucha de clases en la que el socialismo representaba el partido del progreso" (1999: 41).

A la luz del papel de la SDP y las necesidades políticas de la época, se comprenderá su esfuerzo por formalizar una teoría política a través del "socialismo científico", esfuerzo, por cierto, en el que participó 
la totalidad del grupo dirigente de la Segunda Internacional, sobre el entendido que el socialismo era una ciencia a partir de "dos grandes descubrimientos: la concepción materialista de la historia y la revelación del secreto de la producción capitalista, mediante la plusvalía” (Engels, 1967:27). De esta manera, el carácter utópico en el que el socialismo había estado envuelto desde sus inicios era superado. Tras este concepto fue fundamental el ejercicio teórico de Engels que plasmó en su obra “Anti-Duhring” de 1878, como resultado de un conjunto de artículos publicados previamente en la revista Vorwarts de Leipzing, órgano central de la socialdemocracia alemana de la época (Massardo 190-191). Si bien Engels criticó los nuevos sistemas sociales propuestos por los primeros socialistas o llamados socialistas utópicos como Saint-Simon, Fourier y Owen, aclaraba que "a la inmadurez de la producción capitalista y del proletariado como clase, correspondió la inmadurez de sus teorías" (Engels 210).

El socialismo científico, a diferencia del utópico, se presentaba como una certeza religiosa, es decir, la certeza de la fe era sustituida por la fe en la ciencia bajo el entendido que a partir de la aplicación de ciertos instrumentos el proletariado lograría recorrer más rápido el camino de la historia para llegar al socialismo o, en palabras de Engels, al "reino de la libertad”. Así, el adjetivo “científico” portaba en sí la posibilidad de transformar en verdaderas las afirmaciones que toda una generación de marxistas había hecho circular por el mundo (Massardo 195). Desde esta perspectiva, la lucha de clases era la principal obligación de los socialistas para el trazado del camino correcto, la cual se llevaría a cabo en el frente industrial preferentemente a través de la organización de la clase obrera en sindicatos por rama de carácter nacional y también en la política parlamentaria, vislumbrando la fuerza electoral de peso que podían constituir los partidos socialistas y obreros. De esta manera, previo al enfrentamiento total con la sociedad burguesa, el movimiento obrero debía tener existencia propia dentro de esta, explicando ello el carácter reformista y democrático del socialismo en este período (pese a la tensión entre las tendencias "reformistas" y "revolucionarias" dentro del movimiento obrero europeo) y la articulación de una conciencia política de carácter corporativo (Lichthem 1975).

En Chile antes de la institucionalización del socialismo obrero en el Partido Obrero Socialista en 1912, la noción de socialismo circulaba con cierta persistencia en la última década del siglo XIX. Así lo constatan los historiadores Sergio Grez y Jaime Massardo en sus respectivos estudios, remarcando ambos como hito en el itinerario del socialismo el folleto de Víctor Arellano (integrante del Partido Liberal Democrático) El capital y el trabajo publicado en Valparaíso en 1896, donde se reproducen algunos parágrafos de Del 
socialismo utópico al socialismo científico (1883) de Engels. Este último texto parece haber contribuido centralmente a la representación del socialismo en el movimiento obrero que se forma en España y por la vía de la lengua castellana, a los que se van formando, entre otros lugares, como también en Chile (Massardo 192). Grez, en relación a Arellano, sostiene que fue un "francotirador" que actuó de manera aislada, sin crear una instancia colectiva desde la cual difundir sus ideas para que estas se enraizaran en un movimiento orgánico de algún sector social (2011:24).

Independientemente de los distintos enfoques para abordar este suceso, fue un hecho que el ideal socialista se cristalizó en la creación de las primeras tentativas de organizaciones políticas, como fueron la Unión Socialista (1896) y luego el Partido Socialista (1897) en Santiago, así como el Partido Socialista Francisco Bilbao (1898) y su sucesor, el Partido Socialista Científico (1900), también surgidas en la capital. Todas estas experiencias resultaron efímeras y en su mayoría fueron gestadas por disidentes del Partido Demócrata. Es importante mencionar que estas, no tuvieron ningún contacto orgánico con la Internacional Socialista (Massardo 185).

Pese a lo anterior, la intención de crear una colectividad estrictamente obrera y socialista se venía insinuando en el interior del Partido Demócrata (PD) desde comienzo de siglo a través de una tendencia conocida como "doctrinaria", pero la oposición del sector más tradicionalista, identificado como "reglamentario", dirigido por Malaquías Concha, principal líder del partido durante más de tres décadas, no dio chance para provocar un cambio en la orientación y estructura de su partido (Pinto y Valdivia 2001). Cabe identificar estas corrientes y sus disputas, ya que fue aquí donde comenzó a asomarse una diferencia en el terreno ideológico y a gestarse la matriz del socialismo nacional, encabezada en gran proporción por Recabarren.

Sergio Grez, en un artículo acerca de este partido, reconstruye el periplo de estas dos facciones rivales del PD entre 1901 y 1908, período en el cual el partido se fracturó en diversas ocasiones producto de las discrepancias en torno a la política de alianzas o pactos electorales con los partidos burgueses. Si bien esto se presentaba como la principal causa de las diferencias, debido al debilitamiento del eje político que inicialmente los había reunido, es decir, la autonomía partidaria, prontamente las tensiones se incrementaron con la emergencia de un discurso marcadamente más clasista, proveniente de un sector del ala doctrinaria, que proclamó una opción por el socialismo, evidenciándose así distintas posturas sobre 
cómo abordar las necesidades de la lucha social. Aunque esta diferencia se fue haciendo cada vez más notoria a través de ciertas publicaciones periodísticas, la proclamación de candidaturas declaradamente “doctrinarias" y la salida de algunos de sus militantes, "incluso en los momentos de polémica más dura entre las vertientes escindidas de 'la Democracia', las esperanzas en la reconciliación nunca se perdieron completamente. A veces estos deseos se tradujeron en iniciativas al margen de las directivas reglamentaria y doctrinaria", por tanto, la "autonomía absoluta", fue más bien "un recurso discursivo para paliar el descontento que afloraba recurrentemente en su base, pero que no tenía ninguna viabilidad, so pena de ver desaparecer los escasos representantes demócratas de los puestos de representación popular” (Grez 2012).

No obstante, la aparición de un discurso más radical en el seno del partido interpelaba en particular a la dirigencia reglamentaria, la que a modo de defensa reiteraba cuales eran los principios que sostenían a la Democracia, subordinando las luchas sociales a su estrategia de reformas legales y conquista de puestos de representación política electoral y, en cuanto a las formas de asociación popular, mostraron una clara predisposición por el mutualismo. Por su parte, los doctrinarios eran igualmente partidarios de la legislación social, pero más proclives a una práctica más apegada a los movimientos sociales y a impulsar el desarrollo de organizaciones sindicales (sociedades de resistencia, mancomunales y federaciones), muchas veces en conjunto con los anarquistas en torno a una política más decididamente clasista (Grez 2012).

Así, en este proceso de diferenciación, según el citado artículo, el ala reglamentaria comenzó a delimitar las fronteras con el socialismo y anarquismo y, asimismo, el sector socializante de los doctrinarios inició un proceso de definición y distinción entre democracia y socialismo y entre socialismo y anarquismo, destacándose la figura de Recabarren en la fundamentación y articulación de cada uno de los conceptos (en particular del socialismo), implicando estos no sólo formas discursivas diferentes sino también estilos de hacer política y comportamientos disímiles en relación al Estado, los patrones y los movimientos sociales.

Bien es sabido que Recabarren militó en el PD ininterrumpidamente desde 1894 hasta 1912 y fue dentro de esta colectividad que se aproximó a los postulados del socialismo, comenzando a hacer sus propias elaboraciones en torno a este. Sin embargo, su militancia demócrata no le impidió acercarse a los postulados del anarquismo, como afirma Gonzalo Vial: “cuando dirigía La Democracia (1899-1901) 
publicaba artículos libertarios de Alejandro Escobar y Carvallo, anudándose entre ambos, por este motivo, una "elevada amistad intelectual"” (1981: 876). Al avanzar el nuevo siglo se fue distanciando de los anarquistas, coincidiendo las críticas hacia ellos con su propio proceso de ampliación y sistematización de las nociones sobre el socialismo. Fue en su autoexilio en Buenos Aires entre 1906 y 1908 -provocado por la persecución política y judicial-, que se convenció de arrastrar al PD hacia el socialismo, visualizando al Partido Socialista Argentino como modelo para la democracia chilena (Pinto y Valdivia 2001).

Claramente el contexto mundial, atravesado por los sucesos de la Primera Guerra Mundial (1914-1918) y la Revolución Bolchevique (1917), modificó el imaginario socialista instalado bajo la época de la Segunda Internacional, impactando también estos hechos al socialismo en América Latina. En agosto de 1914 se dio término a una forma específica de creer en el internacionalismo, puesto que los principales partidos socialistas europeos -el alemán y el francés- se alinearon con sus respectivas naciones para luego enfrascarse en una matanza mutua. Así, el internacionalismo socialista quedaba desacreditado frente a la fuerza del nacionalismo. Según relata Grez, en Chile todos los dirigentes y militantes del POS condenaron sin matices la guerra y el actuar de ambos bandos beligerantes, "considerados como imperialistas que había que combatir, sentir muy distinto a otros partidos socialistas, como el caso de los argentinos, donde hubo dos posiciones frente a la guerra, precipitando la ruptura de la minoría internacionalista y dando origen en enero de 1918 al Partido Socialista Internacional (PSI), que luego en diciembre de 1920 se transformaría en Partido Comunista de Argentina" (Grez, 2011:154).

La formación del Partido Comunista en Chile (1922) fue la culminación de un proceso que se inició con la adhesión indiscutida de Recabarren y de la dirigencia del POS a la revolución bolchevique y los "maximalistas rusos". El escenario ideológico que dictaminó la transformación del POS en PC fue la adhesión al Komintern o Tercera Internacional Comunista fundada en Moscú en marzo de 1919 (dejando de existir en 1939), cuyos lineamientos apuntaban, bajo los postulados de Lenin, a una dirección centralizada eficaz, personificada en una elite política o de 'revolucionarios profesionales'. En este marco, el partido debía ser independiente y conductor del movimiento obrero. De este modo, el socialismo traspasaba el limitado horizonte de clase del movimiento obrero (Lichthem 1975). 
Por último, el significado de la revolución traspasó las fronteras rusas para convertirse en un ejemplo de referencia obligada para sus seguidores y detractores. En términos de imaginarios, E P Thompson señala que es un "utopismo", bajo la forma de una proyección embellecida y completamente ficticia de la URSS. Esta utopía fue ofrecida a los de fuera como emblema de su propia historia futura, como su propio futuro, glorioso e inexorable (Thompson 1981).

\section{La emergencia discursiva socialista: La FOCH versus Recabarren}

La emergencia del discurso socialista, que en estos años no alcanzó a quebrar el discurso hegemónico, quedó reflejada en el distanciamiento que empezaron a tomar los fochistas de su presidente honorario, el conservador Paulo Marín Pinuer. Hasta la Convención de 1917, los obreros ligados a la FOCH mantuvieron su perfil de sociedad mutualista. Sin embargo, la participación de la FOCH en la huelga ferroviaria de 1916 sentó un precedente en las transformaciones de las prácticas federales, puesto que la huelga apareció por primera vez en la organización como una posibilidad real de defensa ${ }^{8}$.

Como se mencionó anteriormente, la $\mathrm{FOCH}$, en el momento de la institucionalización del socialismo obrero en el Partido Obrero Socialista (POS) en 1912, bajo el liderazgo de Recabarren, no pertenecía propiamente al mundo socialista, pero criticaban la intransigencia que tuvo el POS, específicamente la postura de Recabarren hacia sus prácticas y discursos. A partir de estas críticas comenzó en diciembre de 1913 una polémica entre Recabarren y Gentoso en torno a los significados del socialismo. que, como lo adelantáramos, fue el punto de encuentro entre la FOCH y el socialismo. Pese a que se toma esta fecha como inicio de la disputa, es importante destacar un artículo previo de Recabarren titulado "La Gran Federación Obrera de Chile", publicado en el periódico de Iquique El Despertar de los Trabajadores en mayo de 1913, en el cual se esbozaron los lineamientos, características y tonos de la confrontación. Recabarren expone lo siguiente:

"El clericalismo está introduciéndose al seno mismo de los trabajadores con la habilidad que nunca le falta ha organizado a un buen número de los

\footnotetext{
${ }^{8}$ A partir de la experiencia del conflicto ferroviario y de la huelga de 1916 fue posible observar cómo se fue gestando un discurso diferenciador y crítico al discurso hegemónico de la FOCH, en particular, desde los federados socialistas de Valparaíso en sus modos de enfrentar el conflicto. Este discurso emergente comenzó a crear nuevos significados y valores, nuevas prácticas y relaciones al interior de la FOCH, las cuales fueron desplegando en el trascurso del conflicto una representación del socialismo en torno a la autonomía de la clase obrera con respecto a la burguesía y sus instituciones y a la lucha de clases. Las publicaciones del periódico obrero El Socialista de Valparaíso (1915-1917) expresaron este carácter diferenciador en sus discursos.
} 
trabajadores de los ferrocarriles y con el nombre pomposo de Gran Federación Obrera de Chile ha organizado secciones en todos los pueblos donde hay maestranzas de ferrocarriles.

Una de las costumbres ya establecidas es bendecir en una iglesia el estandarte social y nombrar padrinos a cualquier explotador de los trabajadores que haya gestado más o menos maña para hablar en bien del pueblo mientras sus actos dicen lo contrario o no dicen nada.

A esta obra mistificadora de esa organización están contribuyendo maravillosamente los demócratas.

Nosotros estimamos que esa organización no es otra cosa que un gran narcótico con que engañan y encadenan a los trabajadores, haciéndoles dormir con esperanzas y nada más.

La habilidad con que se desarrolla esa organización hace creer a los inocentes que van a mejorarse con la estúpida táctica de bendecir standartes (sic) y tener padrinos a los burgueses empedernidos.

Los compañeros socialistas que viven cerca de todas las secciones de esa organización deben combatirla enérgicamente antes que abarque $y$ embrutezca a la totalidad de los trabajadores.

Los estatutos de esa gran federación no establecen ninguna reivindicación social ni económica y demuestran ser solamente una sociedad de socorro mutuo como cualquiera otra, con la diferencia que tiende a engañar más disimuladamente a sus incautos asociados, agregando a la organización almacenes llamados cooperativas.

Trabajadores de Chile: la Gran Federación Obrera de Chile, es sólo una hábil trampa destinada a entreteneros por muchos años.

Dejarla crecer es dejar crecer al enemigo" (El despertar de los trabajadores 27 de mayo de 1913).

A partir de este artículo inaugural se expresaba, por un lado, la disputa personal entre ambos dirigentes y, más profundamente, la pugna entre el POS y el Partido Demócrata (en el que militaba Gentoso) y, por otro lado, el rechazo al estatuto y a las prácticas de la FOCH -amparadas por la militancia conservadora de su presidente honorario, Marín Pinuer, y la dirigencia federal de Gentoso-, y al tipo de organización que representaba. Desde entonces, una vez iniciada la polémica, el militante demócrata enfatizó en la distinción existente entre el "socialismo de Recabarren" y el "socialismo", entendido como ideal supremo de justicia y transformación social, con el propósito de distanciarse de su pensamiento.

En primer lugar, la polémica se centró en el clericalismo de la $\mathrm{FOCH}$, expresado en la tradición de bendecir su estandarte social según las prescripciones de la religión católica, y en la militancia conservadora de su presidente honorario. Ante esta acusación, la FOCH se defendió mencionando que no se identificaba con ningún credo religioso. 
Para comprender la postura de Recabarren es necesario hacer mención al profundo sentimiento anticlericalista arraigado en el pensamiento socialista obrero. "El anticlericalismo no era un elemento menor dentro del ideario impulsado por el POS" (Pinto, 1999: 333), puesto que, junto al capital, el clero era visto como uno de los peores males de los pueblos. Las razones de esta irreconciliable relación entre la religión y el socialismo se encontraban, primero, en la creencia de la fe en un mundo mejor después de la vida terrenal, lo que implicaba, a juicio de los socialistas, "mantener a los seres humanos, hasta la muerte bajo la brutalidad abyecta de la resignación ante las cosas creadas por la ignorancia de los hombres de otros tiempos pasados" (332). De la misma forma, cuestionaban la existencia y grandiosidad de Dios, por el hecho de no haber ninguna muestra de justicia y de bondad hacia los sectores desamparados, que constituían una mayoría.

Fueron estos argumentos la base de la crítica a la acción de la Iglesia Católica en los asuntos obreros, considerando su poder una amenaza para las organizaciones de los trabajadores. Más aún, cuando pretendía contrarrestar la acción revolucionaria de los obreros creando nuevas asociaciones, que, en opinión de los socialistas, eran “organismos sedentarios, fanáticos que servían tan solo a los intereses de la iglesia y olvidaban su objetivo principal” (El despertar de los trabajadores 2 de junio de 1915). Se continuaba diciendo, en este mismo artículo, que "quienes predicaban la sumisión y la humildad, la resignación y el servilismo no podían ser partidarios de los trabajadores que necesitaban imponerse frente al capital" (El despertar de los trabajadores). Además, el anticlericalismo recabarrenista derivaba de la estrecha relación entre el Partido Conservador y la Iglesia; en definitiva, entre ésta y el orden sociopolítico interno.

En este contexto es donde se explica la polémica desatada por Recabarren. La discusión puntualmente arrancó con la publicación en La Locomotora de una serie de artículos titulados "Sectarismo Socialista". El primero de éstos apareció el 27 de diciembre de 1913, en el cual Gentoso contestó a los dichos de Recabarren referentes a que la Gran FOCH era sólo una sociedad clerical encaminaba a acorralar a los obreros para garantizar la libertad de explotar. Ante esto, Gentoso replicó que las causas de esos ataques no tenían justificación alguna y solamente se debían a la mala fe, a la intolerancia y al sectarismo del director de El Despertar, afirmando lo siguiente: 
Lo único que nos extraña y que no comprendemos es como en el nombre del socialismo El Despetar ataca y denigra a una sociedad en que militan una enorme cantidad de obreros ferroviarios, que luchan por el mejoramiento económico, social e intelectual de las clases trabajadoras (La Locomotora 27 de diciembre de 1913).

La segunda parte de "Sectarismo Socialista" empezaba con la reproducción de un párrafo escrito por Recabarren, en el cual éste mencionaba lo siguiente:

Día a día crece esa federación obrera, día por día esos borregos desgraciados se remachan con la cadena eclesiástica su propia esclavitud y día por día aumentarán su desventura y sus verdugos que los conduzcan a la esclavitud (La Locomotora $1^{\circ}$ de enero de 1914).

Gentoso, frente a estas palabras, respondió defendiendo el acto de bautizar el estandarte, arguyendo que:

No significa colocarse un yugo servil o atar su porvenir, ni siquiera el indicio de sustentar ideas clericales, sino que la tramitación de una mera fórmula y encaminada a demostrar la más alta prueba del respeto mutuo, que se tienen entre sí, todos los socios de una asociación que no ataca la

Añadió a esto: libertad de conciencia (La Locomotora $1^{\circ}$ de enero de 1914).

"Ningún hombre cuerdo en el dominio completo de sus facultades mentales, puede decir honradamente y obrando de buena fe, que una institución, por el solo hecho de bautizar su estandarte, se haya puesto voluntariamente el más servil de los yugos y haya amarrado todo su porvenir" (La Locomotora $1^{\circ}$ de enero de 1914).

Mediante estas declaraciones, es posible inferir que Gentoso trataba de establecer una diferencia con los conservadores, al aseverar que los federados no sustentaban necesariamente ideas clericales. Quizás, esto puede ser entendido como un indicio para desmarcarse de la figura de Marín Pinuer y comenzar a definirse en términos doctrinarios, pero veremos que, a ojos de Recabarren, no había distinción alguna ya que Gentoso, pese a sus aclaraciones, estaba recurriendo a un lenguaje legitimado en los federados como era la bendición religiosa.

Semanas después, en un escrito de prensa de El Despertar, Recabarren ratificó su crítica a la bendición de estandartes en las secciones de la FOCH y al patrocinio de las autoridades a través de este rito. Su rechazo lo redactó así:

[...] hemos dicho que todas las secciones de esa federación han llevado sus estandartes a la iglesia a recibir la llamada bendición clerical; hemos dicho que los obreros han puesto de padrinos para sus estandartes, en esos actos, 
a los intendentes y primeras autoridades de los pueblos donde se han hecho esas bendiciones, asistiendo a esos actos los obreros (que son los eternos explotados), las autoridades (que siempre serán sus opresores), los diputados (que los agobian con impuestos y autorizan todos los latrocinios) y los patrones que los explotan y los demócratas que los engañan y los venden (El despertar de los trabajadores 24 de enero de 1914).

Además, en esta ocasión, agregó, que “esos actos son también amparados, prohijados y aplaudidos por los demócratas, que pretenden aparecer ante el pueblo como sus defensores”. Más adelante, en este mismo artículo, Recabarren personalizó su impugnación a los demócratas a través de Gentoso, demostrando así que su enfado tenía un doble cariz. Primero era personal, puesto que sacó a colación un antiguo suceso entre él y otros demócratas de entonces, originado en el periodo en que Recabarren había dejado la dirección del diario La Reforma de Santiago en 1907, en el cual fue acusado por la "prensa burguesa" de quedarse con dineros del diario. En referencia a aquella época, Recabarren señaló que "La Reforma me defendió en artículos pateros alabándome, demostraría ese hecho que los demócratas que dirigían $L a$ Reforma, que son los mismo que hoy me calumnian y me acusan falsamente, dejan probado que eran mis cómplices y mis alcahuetes, e individuos que así obran son por cierto asquerosos y despreciables" (El despertar de los trabajadores). Los dardos apuntaban a Gentoso como el principal calumniador.

Por otro lado, el disgusto de Recabarren -izquierdizado desde su traslado a Iquique en 1911- se debía al tipo de organización obrera que propiciaban los demócratas. En este sentido, Recabarren dijo que la aspiración de éstos era "ver confundidos a obreros con explotadores, con opresores, con charlatanes y engañadores, con frailes y esbirros en un solo abrazo y eso nosotros no podemos presenciarlo sin dejar de gritar que eso significa perpetuar la esclavitud obrera" (El despertar de los trabajadores). A raíz de estas palabras, Recabarren aludió nuevamente a Gentoso, llamándolo "rufián clerical". Finalmente, en este número, es menester destacar que el ataque de Recabarren hacia este tipo de acciones lo fundamentó utilizando el socialismo como fuerza de renovación en detrimento de lo que consideraba "prácticas inútiles y agónicas" amparadas por los demócratas, que sólo confundían a los trabajadores. Precisó, en tanto, que los demócratas "no pudiendo atacar la doctrina socialista calumnian a los propagandistas de la doctrina" (El despertar de los trabajadores). Es relevante esta apreciación, puesto que, efectivamente, las réplicas de Gentoso hasta el final de la polémica no fueron contrarias al ideal socialista y a los militantes socialistas, en cambio sí a su principal propagandista. 
Claramente, había una pugna entre el Partido Obrero Socialista y el Partido Demócrata. Por ello, la militancia en el Partido Demócrata de varios de los líderes de los gremios ferroviarios, entre ellos, Gentoso, fue otro eje de la disputa. Recabarren en una columna posterior añadió esta idea:

Democracia es una idea de igualdad política de ampliación de las libertades públicas, a cuya sombra pueden desenvolverse todas las actividades humanas. Los socialistas son todos demócratas. El Partido Demócrata no ha hecho jamás acción democrática. Siempre dio sus votos a los enemigos de la democracia, favoreciendo a la oligarquía chilena; siempre ha dado sus votos a los explotadores del pueblo. No combatimos al ideal demócrata combatimos al Partido Demócrata" (El despertar de los trabajadores 27 de enero de 1915)

La distancia de este partido de las causas obreras o, más bien, el hecho de no ser un partido obrero y su cercanía con el sistema político oligárquico, fue una de las razones por las cuales Recabarren estimaba que los demócratas eran explotadores de los obreros y la Gran Federación Obrera una organización dirigida por ellos para desviar a los trabajadores de su verdadero camino (no debe olvidarse en este sentido que la fundación de la FOCH fue un espacio disputado por los demócratas). A su vez, consideraba torpe la defensa de Gentoso, ya que con ésta estaba protegiendo los intereses de los conservadores, en específico, los de Marín Pinuer. En consecuencia, este hecho, "perpetuaría las costumbres anticuadas e impediría el avance del progreso, materializado en el socialismo" ((El despertar de los trabajadores 12 de febrero de 1914).

Para comprender lo anterior no debe olvidarse la historia del pensamiento socialista de Recabarren y su ruptura con el PD en mayo de 1912 y, por otro lado, el alejamiento de este partido de sus bases obreras producto de la importancia que comenzó a adquirir a nivel nacional con la elección de sus primeros senadores y cargos ministeriales-, lo cual era considerado por el fundador del POS como provechoso para que sus dirigentes hicieran carrera política a costa de los trabajadores. Desde el momento de su distanciamiento con el PD fueron habituales sus denuncias en torno a la costumbre de los partidos burgueses de valerse de los sufragios populares, obtenidos mediante el clientelismo o el cohecho, para consolidar su monopolio sobre los cargos públicos (Pinto y Valdivia 2001). Según él, ejemplos de este aprovechamiento en el seno de la FOCH serían las candidaturas a diputado del conservador Marín Pinuer, en Concepción en 1912, y la del propio Gentoso en 1915.

Bien es sabido que Recabarren permaneció en el PD entre los 18 y 35 años, teniendo allí una militancia vigorosa. El término de su afiliación demócrata fue la base que fundamentó el lugar desde el cual realizó 
sus elaboraciones discursivas en contra de la FOCH que, de paso, como se ha demostrado, fue dejando la estela de las ideas que conformaron su camino hacia su representación del socialismo. El escenario fue Iquique, ciudad donde residió desde 1911 hasta mediados de 1915.

Sin embargo, esta escisión con los demócratas y la implantación del socialismo en Tarapacá -como anota Pinto y Valdivia- no supuso un quiebre con las tradiciones políticas adquiridas en el seno del PD. En este sentido, existe consenso en la historiografía en cuanto a la permanencia y continuidad de éstas en Recabarren, las cuales estaban enraizadas en la historia de las tradiciones democráticas de ciertos sectores progresistas organizados, articulando una determinada representación de la política que podía caracterizarse por la elección de una vía legal e institucional como estrategia de desarrollo de las luchas democráticas, por estimular la libertad de reunión, por la prensa obrera como portavoz para difundir el pensamiento democrático y por la promoción de sus propios cuadros, es decir, de los propios trabajadores en el entendido de que serán los mejores defensores de sus propias reivindicaciones (Massardo, 2008:175). Sin embargo, la continuidad con estas tradiciones políticas no opacó las diferencias ideológicas con la matriz demócrata que Recabarren comenzó a expresar en sus escritos desde 1907 en adelante.

En efecto, la aproximación que tuvo Recabarren a los postulados del socialismo, como se ha mencionado anteriormente, ocurrió siendo militante demócrata y su convicción de arrastrar al PD hacia el socialismo fue ratificada en su autoexilio en Buenos Aires entre 1906 y 1907, provocado por la persecución política y judicial, llevándolo a visualizar al Partido Socialista Argentino como modelo para la Democracia chilena. "En los albores de su estadía comenzó a militar en ese partido, conservando al mismo tiempo su adhesión al PD, indicando esto la asimilación que hizo entre ambos partidos y, por ende, el carácter complementario que democracia y socialismo tenían en ese momento para Recabarren" (Massardo, 2008: 170-171). Sin embargo, la intensidad de esta experiencia, las relaciones que estableció con dirigentes socialistas extranjeros, los viajes a Europa y la recepción de nuevas ideas y definiciones, incidieron en que Recabarren empezara a ampliar y sistematizar las nociones sobre el socialismo y, al mismo tiempo, a tensionar las diferencias entre la democracia y el socialismo. La representación de estos términos quedó plasmada en una serie de artículos titulados "Democracia y Socialismo", publicados en el periódico demócrata La Reforma de Santiago entre diciembre de 1907 y enero de 1908. Se destaca del primer número esta reflexión: 
He estudiado de nuevo ambos programas: el demócrata y el socialista, iy cuán enorme es la diferencia! El programa demócrata parece pálido, insignificante, probando con sus expresiones la poca capacidad moral e intelectual de los obreros de Chile. Sólo contiene un programa de reformas para realizar sobre las instituciones existentes, ampliándolas, suavizándolas, democratizándolas, pero dejándolas siempre lo que son: instituciones coercitivas de la libertad dominada por la burguesía. La democracia proclama reformar instituciones, democratizarlas. El socialismo proclama la desaparición de las instituciones inútiles y el reemplazo de algunas por otras completamente distintas, socializándolas. (La Reforma 22 de diciembre de 1907).

Esta declaración doctrinaria se considera fundacional para su ulterior proyecto de formación de un Partido Socialista en Chile, reparando en que la democracia era un principio insuficiente para satisfacer todas las expectativas del proletariado, puesto que en quince años la representación parlamentaria demócrata no había sido garantía suficiente para mejorar sus condiciones laborales y de subsistencia. No obstante, vemos que hasta aquí el anhelo de Recabarren era asumir una perspectiva socialista desde el PD y llevar a este partido a posiciones socialistas, quedando reflejado en el siguiente párrafo:

Nuestro propósito no es otro que el de provocar, al interior del Partido democrático, una gran corriente de opinión que estudie y discuta estas ideas. Nuestro objetivo no es otro que el de hacer aceptar estas ideas que permitirán al Partido democrático de desarrollarse (sic) y de reforzar su organización (La Reforma 7 de enero de 1907).

Aunque la intención de crear una colectividad estrictamente obrera y socialista se venía insinuando en el interior del PD desde comienzo de siglo a través de la tendencia conocida como “doctrinaria”, la oposición de los sectores más tradicionalistas, identificados como "reglamentarios” (dirigido por Malaquías Concha, principal líder del partido durante más de tres décadas), no dio chance para provocar un cambio en la orientación y estructura de su partido. A su regreso a Chile, Recabarren se incorporó nuevamente a las filas demócratas, pero sus días estaban contados, desencadenando un periplo paralelo y abiertamente disputado con el PD.

Bajo esta constatación, las posturas de Malaquías Concha y Recabarren resaltan en nuestro estudio, en vista de sus tempranas diferencias y, más aún, al ser miembros de una misma agrupación partidaria, explicando así, en parte, la separación definitiva de sus caminos políticos. El "Programa del Partido Democrático" (1887), en su primer artículo, estableció que tenía "por objeto la emancipación política, 
social y económica del pueblo", proceso que se iniciaba con la propia constitución del partido. Este principio se articulaba en la noción de un pueblo carente de libertad e igualdad, debido a que el sistema político oligárquico impedía el ejercicio de tales derechos. El "Manifiesto del Partido Democrático al pueblo chileno" del año siguiente, al respecto señalaba que "al constituirnos en nación independiente y soberana, mediante los esfuerzos del invicto pueblo chileno, establecióse (sic) que el gobierno de la república sería popular y representativo; esto es, que, el pueblo sin coacción de ninguna especie elegiría los poderes del Estado y se daría las leyes que tuviera a bien por medio de sus representantes en el Congreso" (Massardo, 2008: 363). Sin embargo, la representación y el ejercicio de la soberanía del pueblo eran inexistentes ya que la designación de los altos cargos del Estado dependía de la voluntad absoluta del Presidente de la República. En esta lógica, se posaba el artículo $2^{\circ}$ del programa: "Para llenar estos fines se propone trabajar por obtener la debida representación en los diversos cuerpos políticos. Congreso, municipio, juntas electorales, etcétera" (367). De esta manera, se relevaba la "lucha pacífica de las urnas", siendo el sufragio la única arma de combate hacia la emancipación política, social y económica.

"Los desheredados de la fortuna nacen condenados a la miseria y a la ignorancia, al servilismo y al proletariado, su única herencia social, su sola propiedad individual y familiar" (364). Este desalentador pasaje del "Manifiesto" daba cuenta de la condición de inferioridad del pueblo, producto de la negación de la democracia y la perniciosa organización económica, ante lo cual el naciente partido apelaba a las ideas ilustradas de educación laica, libertad, derecho, bienestar para superar el estado de atraso del pueblo, el que impedía su contribución a la civilización e incorporarse a la senda del progreso. Además del compromiso que asumía el PD en la regeneración del pueblo a través de la elección de representantes y la urgencia de implementar una legislación social, sostenía que ese proceso debía ir acompañado de un fomento a la creación de espacios formativos de los principios democráticos, como la organización y la prensa obrera.

Estos principios fundadores del PD, referidos en grandes rasgos, nos aproximan al lugar de enunciación de los discursos de Malaquías Concha y Recabarren en torno a la realidad social observaba. Aunque compartieron una plataforma común, las divergencias se asomaron prontamente en cuanto a la visión que subyacía a la relación entre capital y trabajo. Fue aquí entonces desde donde arrancó el distanciamiento teórico de Recabarren con el PD, al incorporar una vertiente socialista en su seno, implicando un enfoque clasista de la realidad social. En un artículo de prensa titulado "La cuestión social", declaraba: 
La miseria se revuelca y se conmueve airada en el fango de sus desgracias a la vista de la abundancia acaparada. De esta situación nace una agitación de los de abajo que quieren desasirse de las garras de la miseria, sedientos de justicia y de vida contra los de arriba que en su egoísmo se creen con derecho a encarcelar los goces de los pobres y encerrar sus raciones de vida, privándoles de sus derechos sin que exista necesidad ninguna para ello. (La claridad del día 27 de noviembre de 1904).

Por esta lucha entre los de arriba y los abajo, parafraseando a Recabarren, fue que nació la cuestión social. Frente a esto, indicaba que debían proponerse las soluciones, pero no las de los "sociólogos o estadistas de las clases burguesas", que las buscaban dentro del ambiente de las ideas en que vivían. La explicación que éstos daban se remitía a una "cuestión de estómago" y las salidas se traducían en reformar el actual sistema social imperante en el mundo. Recabarren afirmaba que la solución del problema no estribaba allí, puesto que era el sistema el que ocasionaba la desigualdad y la injusticia social. En consecuencia, la salida que comenzó a diseñar Recabarren fue la transformación del estado social vigente por uno nuevo, perfecto y sano, donde los hombres se sintieran felices y libres.

El distanciamiento definitivo de Recabarren del PD se produjo en mayo de 1912 en Tarapacá. En El Despertar de los trabajadores se adujeron los motivos, argumentando: "nos separamos definitivamente por dos razones: porque el Partido democrático ha mostrado a través de su política que no es más útil a los intereses de los trabajadores y porque los dirigentes democráticos son, en su mayor parte, elementos burgueses" (Massardo 174). De esta manera, Recabarren dejaba de concebir al PD como el partido de los obreros.

Es preciso acentuar, como se ha propuesto anteriormente, que el centro de sus críticas fue hacia el tipo de organización que representaba el PD -las que se agudizaron aún más luego de su salida en 1912-, pero no hacia la noción de democracia en cuanto ideal político de la mayoría (ya que la mayoría de la sociedad chilena eran los trabajadores), y de sus posibilidades políticas mediante el sufragio en la lucha antioligárquica. El sustrato tras esta concepción de Recabarren, nos explica Massardo, era la ausencia en los trabajadores y de los sectores populares chilenos de una práctica de libertad, vale decir, "la ausencia en ellos de la construcción de una subjetividad capaz de avanzar a su autorreconocimiento como actores con plenos derechos y, en particular, con el derecho que les otorgaba su condición de mayoría en la sociedad a realizar su propia visión de mundo" (176-177). De este modo, la valoración de la democracia y la libertad 
política, como vehículo para modificar la existencia de aquellos, fue central en el pensamiento de Recabarren, la que persistió más allá de su alejamiento del PD.

Esta reseña sobre Recabarren en los años previos a la polémica con su ex correligionario, nos facilita la comprensión de sus controvertidos artículos, sumado, a su perseverante labor de implantar el socialismo en Tarapacá -en el tiempo de la polémica con Gentoso-, la cual no siempre tuvo los resultados anhelados. Retomando la primera publicación de La Locomotora de diciembre de 1913, observamos que Gentoso no se explicaba cómo, en nombre del socialismo, se atacaba y denigraba a una sociedad (la FOCH) en que militaban una enorme cantidad de obreros ferroviarios - entre ellos prestigiosos miembros del partido socialista- que luchaban por su mejoramiento económico, social e intelectual. Y, en relación a $E l$ Despertar, argumentaba "cómo un órgano que se titulaba socialista, que debía trabajar por estrechar la unión de la clase trabajadora, por organizar y despertar el espíritu de asociación entre los trabajadores, se preocupa de dividir, de desprestigiar y de disolver asociaciones que prestaban reales y positivos servicios" (La Locomotora 27 de diciembre de 1913). Mediante estas aclaraciones en torno al actuar de algunos socialistas que distaban del socialismo "ideal”, probablemente la intención de Gentoso era mantener a la FOCH bajo tutela del PD y así frenar el traspaso de federados demócratas y sin militancia al POS.

Por último, en cuanto a la comprensión del ideario socialista, señaló:

Nosotros no comprendemos así el socialismo, porque nos hemos formado el más elevado concepto de esas doctrinas, las cuales hemos defendido desde la tribuna pública, desde el seno de las asambleas y desde las columnas de la prensa cada vez que la vemos calumniada o atacada. Entre sus socios hay de todos los colores políticos, sin excluir a prestigiosos miembros del Partido socialista, y el presidente de la Junta ejecutiva es un distinguido miembro del Partido Radica. (La Locomotora).

Esto último demostraba la disputa doctrinaria en la cual se habían enfrascado ambos. Gentoso, en sus artículos, comenzó a referirse a Recabarren como "falso apóstol del socialismo", "anti socialista” y "sumo pontífice del socialismo iquiqueño", principalmente por su sectarismo y soberbia, justificando que "la tolerancia y la libertad de conciencia son unas de las virtudes más sublimes del socialismo, y los que insultan y desprestigian las sociedades obreras, por no pensar como ellos, simplemente no son socialistas" (La Locomotora 10 de enero de 1914). Sin embargo, precisó que el resto de los socialistas no eran responsables de la falta de juicio y honradez de algunos de sus miembros, y que ni "el socialismo ni sus doctrinas pueden personalizarse en un hombre, porque esto significaría empequeñecer su ideal" ( $L a$ 
Locomotora 21 de febrero de 1914). Pensaba que los socialistas, al personalizar la doctrina en Recabarren hacían lo mismo que los frailes al divinizar a Cristo con los ideales que, como hombre, predicó a la humanidad.

Ahora bien, para completar la otra parte de la contienda y situarnos en el lugar de enunciación de Gentoso, figura menos conocida, por lo demás, es imperioso entender su imaginario político refiriéndose a las distintas dimensiones de su existencia en su rol de obrero maquinista, de periodista y conferencista y también como militante demócrata, roles que estuvieron siempre imbricados. Osvaldo López lo presenta en su biografía como "un hombre singular, de la pasta que se forjan los apóstoles y los grandes idealistas de la humanidad, de naturaleza mental apasionada de lo bueno, lo justo y lo verdadero" (López: 1912:29). Nació el 21 de septiembre de 1879 y su vida transcurrió entre Valparaíso -su ciudad natal-, Santiago y Coquimbo. Tempranamente se destacó por ser un alumno aventajado, lo que causó la admiración de sus profesores. Sin embargo, su educación en el Liceo de Valparaíso fue truncada, debido a los acontecimientos de 1891, que dio ocasión al asalto y despojo del almacén de su madre, situación que obligó a Gentoso a aprender un oficio para ganarse la vida y ayudarla. Por esta razón, ingresó a la Casa de Máquinas de la Maestranza de Valparaíso a la edad de 14 años.

Ofició como fogonero y mecánico-maquinista. No obstante, su labor de obrero siempre estuvo acompañada de una intensa actividad sindical. Su biógrafo narra que "durante el tiempo que fue fogonero era buscado por todos los maquinistas para redactar los informes de los accidentes que ocurrían a estos en el trayecto, y cuando contaba 15 años fundó la Sociedad de Fogoneros, siendo el cerebro y el todo de esa Institución" (30). Dos años después, comenzó a participar en las luchas políticas del Partido Demócrata como ardiente propagandista sin derecho a voto. En complemento a estas labores enunciadas, se sumó la compra de una imprenta en Santiago - gestión hecha por el propio Gentoso con los maquinistas de la $2^{\mathrm{a}}$ sección- para editar un periódico que defendiese al gremio de maquinistas, fogoneros y los operarios de Ferrocarriles. A partir de esta iniciativa, surgió el periódico titulado La Locomotora ${ }^{9}$, siendo nombrado uno de sus redactores y secretario general de esta sociedad. Este diario, junto a El Trabajo de Coquimbo,

\footnotetext{
${ }^{9}$ Este periódico que apareció a principios de siglo fue el mismo en el cual se llevó a cabo la disputa entre Gentoso y Recabarren años más tarde. Como era habitual en aquel tiempo, la escasa continuidad de los periódicos, y este diario no fue la excepción, desapareció en 1904 y tuvo una segunda época entre 1913 y 1914, también a cargo de Gentoso.
} 
años más tarde, fueron los espacios en los cuales Gentoso pudo desenvolver su pluma y materializar su faceta periodística a favor de los ferroviarios.

En base a lo recién descrito, podemos decir que, desde sus inicios en el gremio ferroviario, Gentoso se involucró rápidamente en la defensa de sus pares en casos de atropellos y abusos que pudieran ejercer las autoridades de Ferrocarriles en contra de ellos. En otras palabras, siempre estuvo cercano a los gremios ferroviarios, de sus reivindicaciones y luchas. La primera aparición pública en este sentido fue a raíz, precisamente, de las publicaciones de La Locomotora en 1901, lo cual encendió la alarma del Director de Tracción y maestranza, Anselmo Moraga, quien amenazó a Gentoso con destituirlo si no hacía desaparecer a la brevedad el periódico. Esta situación lo motivó a reunirse con los maquinistas para exponer la necesidad de mantener el periódico y, de ser ineludible -como subraya López-iniciar una campaña para pedir la destitución del director, aunque esto implicara perder su puesto. Dicho y hecho, “después de 3 meses de continua y ardiente agitación, colectando millares de firmas por todos los pueblos del sur por todas las maestranzas del Estado, por los talleres y fábricas particulares, levantó meetings simultáneos haciendo todos esos gastos de su propio bolsillo, presentó una formidable acusación al Gobierno y al Congreso, y en el seno de las Agrupaciones democráticas de Santiago y Valparaíso, impuso a los Diputados Demócratas el ataque contra el Dios de los Ferrocarriles” (31).

El significado de este hecho, que finalmente fue victorioso para las pretensiones ferroviarias ya que el director fue destituido, fue que sentó un precedente en las próximas luchas lideradas por Gentoso, puesto que, bajo su concepción los conflictos entre el trabajo y el capital podían ser solucionados desde la esfera del Estado, más en el momento que se encontraba el PD a principios de siglo como garante de los derechos de los trabajadores a través de sus representantes legislativos. Se infiere, por tanto, que pudieron haber sido los diputados Malaquías Concha, Artemio Gutiérrez, Francisco Landa y Ascanio Bascuñan (aunque este último era radical) quienes influyeron primeramente en su formación política, pues según la crónica de López, Gentoso tenía una relación fluida y cercana con éstos, como es posible ver en el episodio de la destitución de Moraga ${ }^{10}$.

\footnotetext{
${ }^{10} \mathrm{Si}$ bien no ha sido posible corroborar desde las fuentes la pertenencia de Gentoso al sector "reglamentario" del PD, se infiere a partir de los vínculos con estos políticos mencionados (en especial con Malaquías Concha y Artemio Gutiérrez) que se identificó con esa facción. No obstante, a la luz del estudio de Grez sobre las facciones del PD a principios de siglo, se deduce que perteneció al sector "doctrinario puro" dado su ligazón permanente a la causa obrera y a su impulso en desarrollar organizaciones sindicales más allá del mutualismo.
} 
El trabajo político de este militante demócrata no sólo se materializó en su labor social e intelectual sino también se entroncó con su designación a candidato a diputado por las provincias de Atacama y Coquimbo en 1906. Esta fue la primera designación de por lo menos cuatro en su carrera política; tres en estas provincias y una en Valparaíso en 1915. En ninguna de sus candidaturas logró vencer, argumentando su biógrafo sobre las tres primeras elecciones, que las combinaciones políticas del momento primaron sobre la verdad y la justicia, refiriéndose principalmente a los manejos del Partido Radical.

Volviendo a la polémica con Recabarren, en cuanto a la organización obrera, Gentoso no comprendía que la FOCH, que tenían intenciones loables con respecto a sus obreros, fueran atacadas en lugar de propiciar la unión de los trabajadores sin importar el color político ni la adhesión religiosa. Gentoso estipulaba esto producto de los comentarios de Recabarren:

Hemos dicho que eso es un peligro futuro, porque lejos de ser una organización que dé una doctrina y un rumbo definido a los trabajadores, no es sino una amalgama híbrida, abigarrada que pretende reunir los elementos más heterogéneos en un solo haz, cosa imposible para un buen propósito. (La Locomotora 14 de enero de 1914).

Ante esto, Gentoso se preguntaba “¿es esto socialismo? ¿es esta la labor que corresponde a un líder del Partido Socialista, como lo es Recabarren en Chile? o, ¿desde cuando acá es doctrina socialista el considerar peligro futuro a una sociedad obrera organizada?" (La Locomotora). Con el objeto de brindar respuestas y fundamentos a estas preguntas, publicó en este periódico artículos referentes a la actuación de los socialistas europeos, especialmente de los belgas, con el propósito de dar una muestra pública que los socialistas europeos confraternizaban cordialmente en el campo de la lucha económica con los obreros católicos, señalando que el único divorcio que había entre ellos era en la lucha política. La intención tras esto era esclarecer el verdadero discurso socialista y demostrar que la campaña "disociadora" de Recabarren estaba "reñida con el socialismo". Reproducimos aquí el extracto que incorporó Gentoso de la proclama que los socialistas belgas dirigieron a los obreros católicos para unir sus causas:

La miseria no repara en las condiciones religiosas para instalarse en el hogar, el impuesto de sangre hiere por igual a los pobres católicos o librepensadores; la justicia no es más humana para el obrero de este o del otro culto. Honradamente lo declaramos con toda franqueza, somos contrarios a todas las religiones, porque no creemos en ninguna y porque estamos convencidos que todas son falsas. Pero ante la conveniencia general de la masa obrera, ante el bienestar económico del asalariado, consideramos que no debemos 
hacer prevalecer nuestras convicciones filosóficas cuando vemos que vamos a producir una división en el seno de la sociabilidad obrera y que pueda ocasionar el fracaso completo de una huelga o de una lucha económica cualquiera, y que para triunfar necesita de la unión estrecha de todos los obreros, sean creyentes o no lo sean (La Locomotora 4 de abril de 1914).

La experiencia de los socialismos europeos, en particular de los socialistas belgas e ingleses, fueron una referencia común en ciertas publicaciones obreras de la época para ilustrar ejemplos exitosos de organización obrera y para indicar el camino que debían trazar los obreros chilenos. En el caso concreto de esta referencia, que, si bien tenía un propósito argumentativo y coherente con la polémica, brinda un elemento específico que los obreros en Chile debían replicar según Gentoso. Es decir, para la existencia de una buena asociación obrera no debían importar el color político, el credo religioso y las convicciones filosóficas, puesto que a todos abrazaban la miseria. Se comprende esta alusión debido a que el Partido Obrero Socialista Belga (1885) permitía el ingreso de los sindicatos profesionales, sociedades de socorros mutuos, sociedades cooperativas, círculos de estudio y propaganda y en general podían adherir todos los obreros, así como las personas de los dos sexos que vivían en una localidad donde no existía asociación obrera o socialista afiliada (Massardo, 2008: 235). Lo interesante de este partido habría sido su forma inclusiva de integrar las distintas experiencias asociativas y el crisol de nacionalidades que formaban parte de la sociedad belga, derivando en una fusión de los organismos políticos y económicos de la clase obrera: partido, sindicatos y cooperativas. En efecto, esta referencia a los socialistas belgas fue la base de su repertorio conceptual para defenderse de las impugnaciones de Recabarren, evidenciando, al mismo tiempo, el tipo de organización obrera que quería promover.

Como hemos señalado, la polémica entre ambos dirigentes supuso el inicio de una reflexión en el interior de la FOCH sobre el socialismo, constituyendo una novedad discursiva debido a su instalación. Si bien es el punto de inflexión en torno a la incorporación de este discurso, el concepto socialista no fue exclusivo del militante socialista, puesto que, en este contexto particular del siglo XX -al menos en Occidente-, gozaba de una vigencia plena, por lo cual sus usos y significados fueron variados en relación a los diversos niveles de temporalidades relativas de la realidad social y sus interrelaciones (Koselleck, 2001:10).

Recordemos que en Chile los postulados socialistas empezaron a manifestarse con cierta persistencia durante la última década del siglo XIX. Las declaraciones públicas de adhesión a esa doctrina a través de 
la prensa, libros y folletos provenían mayoritariamente de integrantes del PD doctrinario o no reglamentario, pero también de personas sin filiación partidista o militantes de otras tiendas políticas (Grez, 2011:24). En este sentido, Gentoso, al inicio de la pasada centuria, ya pululaba en la escena gremial ferroviaria investido de demócrata, por lo que probablemente conoció aquellas proclamas referidas a las bondades del socialismo y las primeras tentativas de creación de organizaciones políticas socialistas.

Por otra parte, la forma inclusiva de este dirigente se evidenció desde los inicios de su vida pública, a principios de siglo, en su preocupación por la organización gremial no sólo de ferroviarios, llevándolo a compartir experiencias organizativas con anarquistas como Magno Espinoza, Alejandro Escobar y Carvallo y Esteban Cavieres, ampliando así sus influencias (Grez 2007). La cercanía de Gentoso con ellos permaneció en los años, relatando Osvaldo López que, para las elecciones de 1912, en las que se presentó por tercera vez candidato a diputado por la provincia de Atacama, la campaña política la hizo en compañía de Alejandro Escobar y Carvallo, pero siendo éste ahora un comprometido militante de la Democracia. Su biógrafo la describe así: "la campaña política más hermosa que se tenga memoria en los anales de la Democracia nacional. En dicha campaña, Gentoso y Escobar Carvallo hicieron una gira de tres meses por toda la provincia de Atacama, dando conferencias y celebrando mítins públicos de propaganda y organización democrática" (López 33).

Estos contactos y experiencias conjuntas se comprenden en el marco de la escasa distinción teórica entre democracia, socialismo y anarquía a principios de siglo. Si bien la decantación ideológica iba avanzando, para muchos anarquistas chilenos las diferencias entre estas corrientes eran ante todo de tipo práctico, como la actitud frente al Estado, la política y los movimientos sociales. "Pero los grandes objetivos finales de todas ellas parecían confundirse, del mismo modo que se confundían en el pensamiento de Recabarren y de otros líderes obreros de la época" (Grez, 2007:168). Esta realidad no sólo se dio en la escena nacional, sino que, de acuerdo al estudio de Aricó sobre el marxismo en América Latina, en general, predominó "una multiplicidad de corrientes democráticas revestidas de un fuerte carácter social, de sostenidas esperanzas mesiánicas en una regeneración universal, sin que existiera entre ellas las fronteras más o menos precisas que luego de la revolución de 1848 se fueron estableciendo en Europa" (Aricó 32).

Bajo este contexto, donde los contornos de las ideologías eran borrosos, los niveles de recepción del concepto socialista resultaron difíciles de precisar en el caso de Gentoso, aunque sí es posible intentarlo a 
partir de las aproximaciones a este ideal desde las tradiciones del PD y en las precisiones que comenzó a realizar Recabarren. En cuanto a estas, para hacer un contraste con la trayectoria de Gentoso, Recabarren hacia 1904 veía el socialismo asociado a la mejora de las condiciones de vida de los trabajadores, a la satisfacción de las necesidades humanas concretas, pero no sólo a modo de constatación de esas premisas, sino que comprendidas como un resultado de las contradicciones que estaban presentes en la sociedad chilena. Recabarren utilizó también ese discurso y la palabra socialista para indicar una corriente política al interior del movimiento obrero, representando el socialismo así un medio más, entre otros, de alcanzar cierto fin social y político (Massardo 212).

Tomando esta base, consideramos que las mismas apreciaciones estaban en el repertorio de Gentoso (como de muchos otros dirigentes obreros) y fueron compartidas en su diagnóstico de la realidad social. Ahora bien, la consideración del socialismo como un "medio más" se expresaba en su opinión favorable a este ideal, como se ha hecho mención, pero, entendido como un alto ideal, quizás inalcanzable en nuestro contexto y, a su vez, como un ideal que era posible ejercerlo cotidianamente a través de la práctica gremial. Una forma de vivir este ideal, a su juicio, se daba a través del interés y la discusión de temas concernientes tanto a socialistas como a federados, dejando entrever que estos no eran dos identidades radicalmente opuestas. Las temáticas tratadas en el periódico y las conferencias sobre legislación obrera, instrucción, anticlericalismo, erradicación de vicios, solidaridad obrera, educación de la mujer (y de la niña obrera), sufragio universal y otros, demostraban el alto concepto que tenían de las ideas más avanzadas los miembros de la Federación, por lo tanto, no podían ser "borregos ni clericales los que, respetando las creencias ajenas, proclamaban a la luz pública los ideales más puros del socialismo" (La Locomotora 24 de enero de 1914).

Es posible también encontrar, fruto de la polémica, una definición de socialismo más concisa dada por Gentoso, proveniente de las definiciones del concepto bajo el influjo de la Segunda Internacional y de sus referencias a los socialistas belgas:

El socialismo es una doctrina científica que aspira transformar a la sociedad sin violencia, sin imposición para nadie, sino que por el libre consentimiento de la mayoría de los ciudadanos o habitantes de un país. El socialismo respetando el derecho de todas las conciencias, combate los prejuicios del pasado, y descorre el velo de la ignorancia por medio del convencimiento de la discusión razonada y no por la imposición atrevida de los fanáticos intransigentes. Recabarren en todas sus campañas 
periodísticas en nombre del socialismo destruye la libertad individual y la desconoce por completo" (La Locomotora).

Estas valoraciones sobre el socialismo estaban enunciadas desde su militancia demócrata, pero sin ánimo de romper con ésta ya que, en su concepción, a diferencia de Recabarren, seguían sin ser excluyentes puesto que el socialismo era un "medio más" en un contexto donde las organizaciones obreras estaban instaladas en un terreno "más democrático y reformista social, antes que socialista" (Aricó 1999: 43). En cambio, el socialismo de Recabarren estaba en una búsqueda de una representación desmarcada del Partido Demócrata, es decir, en un proceso de conformación del ideal como un único medio para alcanzar un fin a través de un partido socialista. De este modo, se comprende la polémica entre ambos y, en particular, el tono de la confrontación impuesta por Recabarren, necesitado de diferenciar el naciente POS respecto de su "padre": el PD.

Por último, las diferencias entre la FOCH y Recabarren también se evidenciaron en torno a la huelga que realizaron los trabajadores a jornal de ferrocarriles (palanqueros y cambiadores) de Valparaíso en octubre de 1913, producto de la proclamación de un decreto ministerial que obligaba al personal a fotografiarse con fines identificatorios. Muchos trabajadores rechazaron cumplir con esta medida por temor a que aumentara el poder de represalia de la empresa, pero el gobierno no aceptó discusión argumentando que era necesario para evitar pérdidas por robo. Ante la imposibilidad de llegar a un acuerdo, los trabajadores declararon la huelga y, a pesar de que el decreto ministerial no se llevó a cabo por el momento, el movimiento no concluyó bien por falta de apoyo. Paulatinamente se incorporaron a la huelga otros sindicatos como los maquinistas, pero la FOCH no adhirió. Santiago Ramírez, Presidente de la Federación de Empleados a Jornal de Valparaíso, envió a raíz de esto, una carta a El Despertar para "aclarar los elementos que componen la famosa Gran Federación Obrera de Chile”, en la cual expresó: "nosotros tenemos que censurar la cobarde actitud que asumieron los federados de la nombrada institución en la huelga (...). Son los únicos culpables que hayamos fracasado" (El despertar de los trabajadores 3 de febrero de 1914). Los reproches a la postura de la FOCH, seguro también provinieron de la recién formada Federación Obrera Regional de Chile (FORCH), organización gremial de resistencia anarquista, que también participó en este movimiento huelguista. Grez menciona, en relación a la opinión de los anarquistas sobre la FOCH, que "los libertarios aplaudieron su surgimiento, pero a muy poco andar, sus esperanzas se vieron defraudadas, puesto que no se convirtió en un centro de reagrupación de las sociedades de resistencia que impulsara la acción directa, siguiendo, en cambio, un curso de acción 
moderada de acuerdo a los principios mutualistas, lo que le valió la crítica implacable de los anarquistas" (2007:227).

Gentoso ante estas críticas justificó su postura:

Declararlas porque sí, como lo sostiene el farsante de Recabarren, es una calaverada y más que esto un crimen imperdonable que cometen los que lanzan descabelladamente a los obreros a una huelga en que no hay probabilidades de éxito. El atacar y calumniar a una sociedad porque no es francamente religiosa y porque no se declaró en huelga es una estupidez. sectaria que ningún socialista juicioso y perspicaz puede aceptar en nombre del socialismo (La Locomotora 28 de marzo de 1914).

La FOCH, en palabras de Gentoso, sostenía que la huelga era una poderosa arma, pero siempre y cuando estuviera bien organizada y estallara en un momento preciso para que las reivindicaciones obreras tuvieran posibilidades de triunfo. Para lo cual, era necesario que la asociación que la emprendiera tuviera los recursos suficientes y una sólida organización.

Un factor importante para este pensamiento, como se ha mencionado, fue la clara influencia y cercanía con el PD y, a su vez, la tradición negociadora de los gremios ferroviarios. Por otra parte, la FOCH probablemente representaba más a los trabajadores a contrata que a jornal y, a los más calificados que a los menos, por lo que no iba a arriesgar una derrota.

No obstante, a la luz de la prensa fochista, se constata que las diferencias entre Recabarren y Gentoso no impidieron la incorporación de socialistas a la FOCH (ex militantes del PD, de otras tiendas o independientes), incluso más temprano de lo pensado. El primer indicio fue entregado por el propio Gentoso en respuesta a Recabarren: "en la FOCH entre sus socios hay de todos los colores políticos, sin excluir a prestigiosos miembros del Partido Socialista, y el presidente de la Junta Ejecutiva es un distinguido miembro del Partido Radical” (La Locomotora 27 de diciembre de 1913). Por otro lado, el consejo federal de Concepción en mayo de 1914 envió a la Junta Ejecutiva de Santiago una nota con el objetivo de desmentir los artículos publicados en El Despertar, a causa de la acusación a la FOCH de estar influenciada por el clericalismo. Se señala en esta carta que la tolerancia es lo que había caracterizado a su consejo, lo cual había permitido reunir a obreros de distintas religiones y bandos políticos. Prueba de ello, era la bendición del estandarte y una campaña anti clerical llevada a cabo en Concepción en la que no hubo protesta de ningún federado. Por último, se enfatizaba que para quienes era más extraña esta 
odiosa campaña era para "los correligionarios del señor Recabarren que, en número considerable, son al mismo tiempo tenaces propagandistas de la FOCH y convencidos e incansables defensores del socialismo, sin que por esto se vean jamás discordias internas en nuestro consejo" (La Locomotora $1^{\circ}$ de mayo de 1914).

Si bien a través de estos escritos encontramos una sensibilidad socialista en el interior de la FOCH, vaga y ecléctica como era ese pensamiento en el Chile de la época, aún no es suficiente para una cristalización del discurso socialista más allá de la incorporación del concepto y la formalización de sus diferentes interpretaciones mediante la polémica recién analizada. Hasta fines de 1914 no es posible develar a aquellos federados que se definían socialistas y tampoco si eran o no militantes del POS. La visibilización de una identidad socialista comenzará a verificarse durante el conflicto ferroviario de 1916.

En todo caso, lo concluyente de estas discusiones fue sin duda que confirmaron la incipiente instalación -tal vez presionada por las mismas críticas- de las categorías "socialismo" y "socialista" en los discursos de la FOCH previo a la hegemonía del socialismo de Recabarren en la Convención de 1919, así como el principio del interés por empezar a comprender y definir el socialismo, sus diferentes interpretaciones y las luchas gremiales y políticas que nutrieron dicha polémica. El socialismo como discurso será después más fácilmente desarrollado al interior de la $\mathrm{FOCH}$, pero no exento de polémicas, tras aquella Convención, gracias a esta temprana instalación.

\section{A modo de conclusión}

El propósito de este artículo fue analizar la emergencia e incorporación del discurso socialista en la Federación Obrera de Chile entre 1913 y 1915, a través de las polémicas de prensa entre Gentoso y Recabarren. Los aspectos que envolvieron dichos artículos estuvieron relacionados con el anticlericalismo, la dirigencia demócrata de varios dirigentes fochistas, el tipo de organización que representaba la $\mathrm{FOCH}$ y la huelga. Estos aspectos claramente fueron el resultado de las duras críticas que Recabarren escribió y divulgó en contra de la FOCH. Gentoso, por su parte, frente a estos ataques comenzó a argumentar férreamente que el "socialismo de Recabarren" distaba del "socialismo", entendido como ideal supremo de justicia y transformación social, iniciándose así una controversia que no sólo demostró ser una rencilla entre dos ex correligionarios del PD, sino que una disputa de tipo doctrinaria. También demostró la polisemia de la voz socialista en la FOCH de entonces. 
Este fue el primer encuentro - o desencuentro y fricción- entre la FOCH y el socialismo, constituyendo el punto de inflexión en el proceso de trasformación al socialismo, debido a que constató la incipiente instalación de este ideario en términos discursivos, habilitando, de esta manera, el camino para implementar los cambios requeridos después de la Convención de 1919. Sumado a esto, el conflicto también mostró a los idearios políticos que disputaban a la FOCH en un contexto donde los contornos de las ideologías eran borrosos.

Ciertamente, el término de la afiliación demócrata de Recabarren en mayo de 1912 y la consecuente formación del POS, fueron las bases que fundamentaron el lugar desde el cual realizó sus elaboraciones discursivas en contra de la $\mathrm{FOCH}$, que, de paso, fueron dejando la estela de las ideas que conformaron su camino hacia su representación del socialismo.

Por su parte, Gentoso en su reflexión sobre el socialismo fue esbozando una serie de consideraciones en torno a su significado, implicando en primera instancia la denominación de una corriente política al interior del movimiento obrero, representando así al socialismo como un "medio más" entre otros para alcanzar ciertos fines políticos y sociales. Tras ello se expresaba una opinión favorable, entendido como un ideal inalcanzable aún en nuestro contexto, pero, a su vez, consideraba que era posible ejercerlo cotidianamente a través de la práctica gremial. Una forma de vivirlo, a su juicio, se daba a través del interés y la discusión de temas concernientes tanto a socialistas como a federados.

Hacia fines de 1914, pese a las referencias alusivas a la incorporación de socialistas a la FOCH, no fue posible develar a aquellos federados que se definían socialistas, y tampoco si eran o no militantes del POS. Sin embargo, la presencia de una identidad socialista comenzó a verificarse muy poco tiempo después durante la huelga ferroviaria de 1916.

\section{Referencias bibliográficas}

Aricó, José (1999), La hipótesis de Justo. Escritos sobre el socialismo en América Latina, Buenos Aires, Editorial Sudamericana.

Engels, Friedrich (1967), El anti-Dühring o la revolución de la ciencia de Eugenio Dühring, Buenos Aires, Claridad. 
Grez, Sergio (2000), "Transición en las formas de lucha: motines peonales y huelgas obreras en Chile (1891-1907)", Historia (Santiago), vol.33, pp. 141-225.

(2007), Los anarquistas y el movimiento obrero. La alborada de "la Idea" en Chile, 18931915, Santiago, LOM Ediciones

LOM.

(2011), Historia del Comunismo en Chile. La era de Recabarren (1912-1924), Santiago,

(2012) "Reglamentarios y doctrinarios: las alas rivales del Partido Democrático de Chile (1901-1908)". Cuadernos de historia (Santiago) (37), 75-130.

Koselleck, Reinhart (2001), Los estratos del tiempo: estudios sobre la historia, Barcelona, Paidós.

Lichthem, George (1975), Breve Historia del socialismo, Madrid, Alianza Editorial.

Massardo, Jaime (2008), La formación del imaginario político de L.E Recabarren. Contribución al estudio crítico de la cultura política de las clases subalternas de la sociedad chilena, Santiago, LOM

Pinto, Julio y Valdivia, Verónica (2001), ¿Revolución proletaria o querida chusma? Socialismo y alessandrismo en la pugna por la politización pampina (1911-1932), Santiago, LOM.

Pinto, Julio (1999), “Socialismo y Salitre: Recabarren, Tarapacá y la formación del Partido Obrero Socialista", en Historia $N^{\circ} 32$, PUC.

Thompson, Edward P (1981), Miseria de la teoría, Barcelona, Crítica-Grijalbo.

Williams, Raymond (1980), Marxismo y Literatura, Barcelona, Península.

Fuentes primarias:

El Despertar de los Trabajadores, Iquique, 1912-1921.

La Locomotora, Santiago, 1912-1915.

López, Osvaldo, Diccionario biográfico obrero, Santiago, Impr. y Enc Bellavista, 1912. 